\title{
Observations on Scots pine mycorrhizae in the surroundings of a fluting mill
}

\author{
TOINI HOLOPAINEN and SAILA VAITTINEN
}

\begin{abstract}
Holopainen, T. \& Vaittinen, S. 1988: Observations on Scots pine mycorrhizae in the surroundings of a fluting mill. - Karstenia 28:35-39.

The distribution of Scots pine mycorrhizal types and the cytopathology of selected mycorrhizae were studied in the surroundings of a fluting mill in Central Finland. A decrease in the mycorrhizal types was observed in the close vicinity of the factory. The mycorrhizae showed several disturbances in their ultrastructure, the most important being accumulation of tannins in the root cortical cells, intracellular penetration by the ectomycorrhizal fungi and accumulation of electron-dense deposits in the fungal vacuoles. The trees with only slight crown injuries showed clear injuries in their rootlets and mycorrhizae. A rapid staining method, Ponceau S, was tested for staining pine mycorrhizae and the results of some staining trials are reported.
\end{abstract}

Toini Holopainen \& Saila Vaittinen, Dept. of Environmental Hygiene, Univ. of Kuopio, PO Box 6, SF-70211 Kuopio, Finland

\section{Introduction}

Compared with the extensive information on the injuries of the above-ground parts of conifers in polluted areas, knowledge of the effects of atmospheric fallout and soil acidification on mycorrhizae is limited. The few experiments carried out with simulated acid rain have all shown unfavourable effects on the infectivity and development of mycorrhizae in conifers (Stroo \& Alexander 1985, Dighton \& Skeffington 1987). In forest decline areas, the root systems of Norway spruce have been studied and several undesirable changes, such as decreased ramification, decline of mycorrhizae and poor cortical development, have been described (Meyer 1985, 1987, Blaschke 1986).

In the present study, samples of Scots pine mycorrhizae were collected from the surroundings of a fluting mill with relatively high emissions of sulphur dioxide and nitrogen compounds. Besides studies of the distribution of different mycorrhizal types, cytopathological methods were applied to reveal cellular symptoms in the fine roots and mycorrhizae of trees with different levels of crown injury.

\section{Materials and methods}

The study area and sampling

The study sites were situated in the surroundings of a fluting mill (Metsäserla Ltd., Savon Sellu factories situated $7 \mathrm{~km}$ NE of Kuopio, Central Finland), which operates on an ammonium sulphite process. The most important emissions are $\mathrm{SO}_{2}(12000 \mathrm{t} / \mathrm{a}), \mathrm{NO}_{\mathrm{x}}(900$ t/a) and $\mathrm{NH}_{3}(20 \mathrm{t} / \mathrm{a})$. Ten sites were selected in predominantly Scots pine forest along a NE transect at distances of 0.4 to $22 \mathrm{~km}$ from the factories. Additional control samples were collected from Suonenjoki about $50 \mathrm{~km} \mathrm{SW}$ of the town of Kuopio.

At each site root samples were taken from the humus layer beneath several Scots pine trees in late June and in October 1987. During sampling, the visible condition of the trees was recorded according to a 5-stage (I-V) scale (Jokinen 1978) and humus samples were taken for chemical analysis $\left(\mathrm{NH}_{4}-\mathrm{N}\right.$, $\left.\mathrm{NO}_{3}-\mathrm{N}, \mathrm{S}, \mathrm{Mg}, \mathrm{K}, \mathrm{Ca}, \mathrm{pH}\right)$. The fine roots $(<2 \mathrm{~mm})$ were collected from the humus layer of core samples $6 \mathrm{~cm}$ in diameter and the percentage of different mycorrhizal types and the weight of the fine roots were determined. 


\section{Identification and staining of mycorrhizae}

The fine roots were classified according to the sheath or surface structure and branching habit. The classification was based on the system used by Mikola and Laiho (Laiho et al. 1987), but some extra classes were added to make the system more sensitive to environmental changes.

During this study we tested the Ponceau S staining introduced by Daughtridge et al. (1986) for identification of infected fine roots in oak. This is a simple technique enabling routine staining of large root materials. The thoroughly cleaned roots were stained in a $10 \%$ solution of glacial acetic acid ( $\mathrm{v} / \mathrm{v})$ containing $0.1 \%$ Ponceau S (acid red 112, Sigma Chemicals), the solution being gently shaken by hand for $10 \mathrm{~min}$. Upon removal from the staining beaker, the roots were rinsed in $10 \%$ glacial acetic acid to remove the surplus stain and then in distilled water, after which they were ready for observation under a dissecting microscope.

Some series of root material were also stained with trypan blue in lactophenol (e.g. Wilcox 1982), which is widely used to reveal fungal infection in plant roots. The cleaned roots were placed in beakers which contained enough $10 \% \mathrm{KOH}$ to cover them and incubated in boiling water for $10 \mathrm{~min}$ to $1 \mathrm{~h}$. They were then rinsed in distilled water with 3 changes and in $2 \% \mathrm{HCl}$ for $3 \mathrm{~min}$, after which they were stained in $0.05 \%$ trypan blue for $30 \mathrm{~min}$. The stained roots were stored in lactic acid if necessary.

\section{Ultrastructural studies}

Four different mycorrhizal types were sampled (when available) from the different study sites for detailed ultrastructural studies. These types were Cenococcum graniforme mycorrhizae, short-branched thin-sheathed brown mycorrhizae, light-sheathed short-branched mycorrhizae ("Suillus type") and unsheathed monopod rootlets (partly nonmycorrhizal).
The thoroughly washed rootlets were fixed in $2.5 \%$ glutaraldehyde in $0.1 \mathrm{M}$ phosphate buffer overnight $\left(+6^{\circ} \mathrm{C}\right)$ and postfixed in $1 \% \mathrm{OsO}_{4}$ for $4 \mathrm{~h}$ $\left(+6^{\circ} \mathrm{C}\right)$, dehydrated in a graded ethanol series and infiltrated in Ladd's LX 112 epon. An infiltration period of up to 3 days was used, because conifer mycorrhizae are especially difficult to infiltrate properly. The thin sections were stained on grids with uranyl acetate and lead citrate.

\section{Results and discussion}

Identification and staining of mycorrhizae

In the preliminary studies we used a classification distinguishing 12 structurally different types of Scots pine mycorrhizae. The classification system is still under development and more types seem to be identifiable, e.g. on the basis of artificial synthesis of mycorrhizae from pure cultures and electrophoretic isoenzyme studies on cultured and field material.

At the background sites, 8 to 10 different mycorrhizal types were usually found in the humus layer of the core samples. At the sites situated close to the Savon Sellu factories a decrease in the mycorrhizal types was observed, 3 to 5 types being typically present. One species, Cenococcum graniforme, dominates in the most polluted sites (400-1 $200 \mathrm{~m} \mathrm{NW}$ ), forming $25-35 \%$ of the total mycorrhizae, while at the control sites the proportion of this species was $2-8 \%$ of the total mycorrhizae. An increase in dead mycorrhizae was observed in some of the sites closest to the factories.

According to Daughtridge et al. (1986) and our own observations, Ponceau $S$ staining reveals the living (active) mycorrhizae by staining the living fungal hyphae with a bright red colour. The nonmycorrhizal rootlets retain the light brown and old (dead) mycorrhizae the dark brown colour. Tables 1 and 2 show examples of staining trials in which thoroughly washed roots were first observed without staining,

Table 1. Staining of Scots pine mycorrhizae in humus samples collected from a control area in Suonenjoki.

\begin{tabular}{lccr}
\hline Type of mycorrhiza & Unstained & Ponceau S & Trypan blue \\
\hline Unsheathed monopods & 892 & 272 & 203 \\
Short thin-sheathed dichotoms & 262 & 145 & 41 \\
Long thin-sheathed dichotoms & 126 & 33 & 31 \\
Piloderma bicolor & 14 & 13 & - \\
Cenococcum graniforme & 49 & 45 & - \\
White-sheathed with rhizomorphs & 56 & 55 & 281 \\
Total & 1399 & 562 & \\
\hline
\end{tabular}


Table 2. Staining of Scots pine mycorrhizae in seedling material (2A bare-rooted seedlings) from Suonenjoki nursery.

\begin{tabular}{lccc}
\hline Type of mycorrhiza & Unstained & Ponceau S & Trypan blue \\
\hline Unsheathed monopods & 374 & 105 & 53 \\
Short unsheathed dichotoms (ectendo) & 337 & 104 & 32 \\
Long thin-sheathed dichotoms & 219 & 138 & 70 \\
Piloderma bicolor & 4 & 4 & - \\
Cenococcum graniforme & 20 & 20 & 15 \\
Dirty white tuber & 25 & 18 & - \\
Total & 979 & 389 & 170 \\
\hline
\end{tabular}

subsequently stained with Ponceau S and finally with trypan blue.

In the first material (Table 1), comprising 1399 rootlets from mature pine trees growing in a background area, 6 different types of rootlets were distinguished. The second material (Table 2) was nursery $2 \mathrm{~A}$ seedlings (Suonenjoki) containing a total of 979 rootlets belonging to 6 different types. In both the materials those types which were unsheathed or had a thin sheath, about one third of the rootlets, stained clearly with Ponceau S. According to the structural characters (swelling of rootlets, presence of sheath, colour) the unstained rootlets were nonmycorrhizal or old without a living fungal component. In contrast, the types with a well-developed sheath $(P$. bicolor, white-sheathed species, tubers) almost all had a positive staining reaction. It is noteworthy that the original sheath colour is usually retained after Ponceau S staining at an identifiable level.

The nursery material also contained ectendotrophic mycorrhizae, as described by Mikola (1965), which was verified with light and electron microscopic studies. The typical unsheathed short dichotomous mycorrhizae formed by the ectendotrophic fungus stained well with Ponceau S. We also tested frozen $\left(-24^{\circ} \mathrm{C}\right)$ root material stored up to 9 months and found good staining of mycorrhizae with Ponceau S within 2 to 3 days after thawing.

Trypan blue staining after clearing of the roots with boiling $\mathrm{KOH}$ solution produced a relatively faint blue colour in the Scots pine mycorrhizae. The clearing procedure also caused severe destruction of the fragile pine root material, breaking off whole rootlets or branches of the mycorrhizae especially from the tuberous forms. The final harvest of the rootlets after trypan blue staining was therefore clearly lower (Tables 1 and 2) than after Ponceau S.
Several different mycorrhizal types can be identified from Scots pine roots without any staining. However, the pine root samples often contain large numbers of unsheathed monopod rootlets or thin unsheathed dichotomous rootlets which may or may not be mycorrhizal. Ponceau S seems to be a practical staining method for identification of mycorrhizal rootlets, especially when it is necessary to distinguish the active mycorrhizae from nonmycorrhizal and old rootlets. Because of the detachment of rootlets trypan blue staining cannot be recommended for practical staining of pine mycorrhizae.

\section{Ultrastructural observations}

The light and electron microscopic studies revealed well-developed ectomycorrhizae in the samples of all studied types of rootlets, with the exception of the monopod roots, part of which were nonmycorrhizal, especially in the polluted sites. The typical structure of a normal mycorrhiza formed by Cenococcum graniforme is seen in Figs. 1 and 2, showing the Hartig net and sheath, respectively.

The ultrastructural changes observed in the rootlet types from the polluted environment were qualitatively very similar. First there was an increase of tannic substances in the root cortical and stelar parenchyma cells. This phenomenon was especially clear in the monopod roots with poor mycorrhizal development. Secondly, the normally ectomycorrhizal fungi were observed to penetrate intracellularly into the deep cortical layers close to the endodermis. This symptom was especially clear in C. graniforme (Fig. 3) but was observed to a smaller extent in all the other mycorrhizal types. Several times direct penetration by the living Hartig net of living cortical cells was ob- 

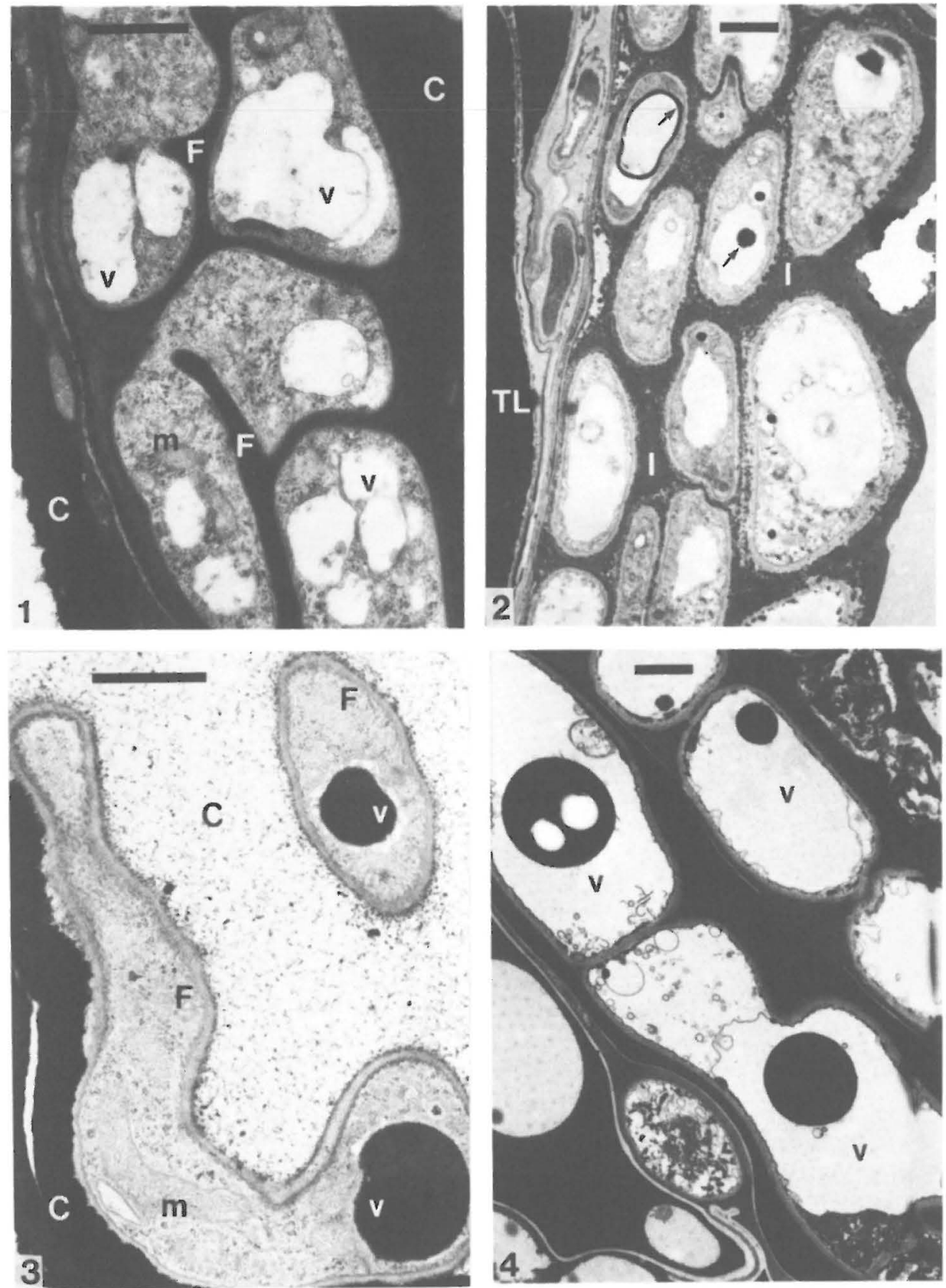

Figs. 1-4. - 1: The Hartig net structure in a control sample of Cenococcum graniforme, showing typical folded fungal (F) structure between the root cortical $(\mathrm{C})$ cells. $\mathrm{v}=$ vacuoles, $\mathrm{m}=$ mitochondria. -2 : Typical pseudoparenchymatous sheath structure in a control sample of $C$. graniforme mycorrhiza, showing vacuolated fungal cells with small electron-dense deposits (arrows). The electron-dense intermedium (I) is typical of the $C$. graniforme sheath. The tannic layer (TL) is visible at the left. -3 : $C$. graniforme mycorrhiza from a polluted site ( $950 \mathrm{~m} \mathrm{NW}$ of Savon Sellu), showing fungal hyphae (F) penetrating a cortical cell (C). Note also the large electron-dense deposits in the fungal vacuoles $(\mathrm{v}) ; \mathrm{m}=$ mitochondria. - 4: Inner sheath structure from a $C$. graniforme mycorrhiza (950 m NW of Savon Sellu), showing aging fungal cells with large deposits of electron-dense material inside the large vacuoles $(\mathrm{v})$. Scale $=1 \mu \mathrm{m}$ in all figures. 
served. Therefore, confusion of these fungi with saprophytes and pathogens is unlikely.

In all types of rootlets collected from the surroundings of the fluting mill, the fungal cells had large electron-dense deposits inside their vacuoles (Figs. 3 and 4). These deposits were especially abundant in the sheath (Fig. 4), but also appeared in the internal parts of the mycorrhiza, including those penetrating the cortical cells (Fig. 3). These deposits were visible in the senescing fungal cells as well (Fig. 4). The chemical constitution and function of these deposits are still unclear, but the same kind of deposits have been described in the algal and fungal cells of epiphytic lichens exposed to nitrogen compounds (Holopainen \& Kärenlampi 1985).

All the structural disturbances described above were also observable in the roots of Scots pine trees which showed only slight injuries (stage II) in their crown and were growing at a distance of $1800 \mathrm{~m}$ from the fluting mill. Analysis of samples from the sites located further along the NE transect is in progress.

\section{Conclusions}

Structural changes indicating serious disturbances in the symbiotic relationship between Scots pine and several mycorrhizal fungi were apparent in an industrial environment. At the moment the principal causal agents of these injuries cannot be identified, because of the presence of several pollutants, affecting the trees both directly and indirectly. Further experimental studies with single stress factors (e.g. nitrogen, sulphur, aluminium, acidity) and their interactions are needed. The Ponceau S staining method proved to be helpful in distinguishing active mycorrhizae from nonmycorrhizal rootlets or old mycorrhizae. This information is important in comparing the vitality of conifer roots in polluted and unpolluted areas.

\section{References}

Blaschke, H. 1986: Einfluss von saurer Beregnung und Kalkung auf die Biomass und Mykorrhizierung der Feinwurzeln von Fichten. - Forstw. Cbl. 105:324-329.

Daughtridge, A.T., Boese, S.R., Pallardy, S.G. \& Garrett, H.A. 1986: A rapid staining technique for assessment of ectomycorrhizal infection of oak roots. Can. J. Bot. 64:1101-1103.

Dighton, J. \& Skeffington, R.A. 1987: Effects of artificial acid precipitation on the mycorrhizas of Scots pine seedlings. - New Phytol. 107:191-202.

Holopainen, T. \& Kärenlampi, L. 1985: Characteristic ultrastructural symptoms caused in lichens by experimental exposure to nitrogen compounds and fluorides. - Ann. Bot. Fennici 22:333-342.

Jokinen, J. 1978: Valkeakosken puustovauriot. - Ilmatieteen laitos, Tutkimusseloste 77, Ilmansuojelu: 1-26.

Laiho, O., Sarjala, T., Hyvärinen, R. \& Rautiainen, L. 1987: Lannoituksen vaikutus männikön mykoritsoihin. - Folia Forestalia 699:1-22.

Meyer, F.H. 1984: Mykologische Beobachtungen zum Baumsterben. - Allgemeine Forstzeitschrift 9:212-228.

Meyer, F.H. 1987: Der Verzweigungsindex, Ein Indikator fur Schäden am Feinwurzelsystem. - Forstw. Cbl. 106: 84-92.

Mikola, P. 1965: Studies on the ectendotrophic mycorrhiza of pine. - Acta For. Fenn. 79:1-56.

Stro0, H.F. \& Alexander M. 1985: Effect of simulated acid rain on mycorrhizal infection of Pinus strobus L. Water Air Soil Pollut. 25:107-114.

Wilcox, H.E. 1982: Morphology and development of ectoand ectendo-mycorrhizae. - In: Schenck, N.C. (ed.), Methods and Principles of mycorrhizal research: 103-113. American Phytopathological Society, St. Paul, MN.

Accepted for publication on 10 June 1988 